\title{
A Compendious Study of Online Payment Systems: Past Developments, Present Impact, and Future Considerations
}

\author{
Burhan Ul Islam Khan \\ Department of ECE \\ Kulliyyah of Engineering \\ IIUM, Malaysia
}

\author{
Adil Ahmad Langoo \\ Graduate School of Management \\ IIUM, Malaysia
}

\author{
Rashidah F. Olanrewaju \\ Department of ECE \\ Kulliyyah of Engineering \\ IIUM, Malaysia
}

\author{
Asifa Mehraj Baba \\ Department of ECE \\ School of Technology \\ IUST, Kashmir
}

\author{
Shahul Assad \\ Department of Management Studies \\ University of Kashmir, Kashmir
}

\begin{abstract}
The advent of e-commerce together with the growth of the Internet promoted the digitisation of the payment process with the provision of various online payment methods like electronic cash, debit cards, credit cards, contactless payment, mobile wallets, etc. Besides, the services provided by mobile payment are gaining popularity day-by-day and are showing a transition by advancing towards a propitious future of speculative prospects in conjunction with the technological innovations. This paper is aimed at evaluating the present status and growth of online payment systems in worldwide markets and also takes a look at its future. In this paper, a comprehensive survey on all the aspects of electronic payment has been conducted after analysis of several research studies on online payment systems. Several online payment system services, the associated security issues and the future of such modes of payment have been analysed. This study also analyses the various factors that affect the adoption of online payment systems by consumers. Furthermore, there can be seen a huge growth in mobile payment methods globally beating both debit and credit card payments, all due to the convenience and security offered by them. Nevertheless, various obstacles have been identified in the adoption of online payment methods; thus, some measures have to be taken for granting this industry a hopeful future. Thus, there should be a suitable trade-off between usability and security when designing online payment systems in order to attract customers. Also, technical and organisational issues which arise in the attempt to achieve interoperability must be taken into consideration by the designers. As a matter of fact, the process of developing interoperable and flexible solutions and universal standards is one of the most difficult tasks in the future ahead.
\end{abstract}

Keywords-E-Commerce; Online payment system; Online payment developments; Payment gateway; Online payment challenges

\section{INTRODUCTION}

E-commerce (or electronic commerce) is among the most popular services that emerged as a result of the propagation of

This work was partially supported by Ministry of Higher Education Malaysia (Kementerian Pendidikan Tinggi) under Research Initiative Grant Scheme (RIGS) number RIGS 16-357-0521. the Internet all over the world [1]. The recent advancements in technology for designing mobile devices coupled with the rising Internet speed as well as mobile technology have made it possible for users to utilise those devices at any location and time for performing electronic commerce transactions besides services like reading e-mails and Web browsing [2][3]. In person trading of products and services between two parties goes back to before the start of written history. With time, as exchange turned out to be more muddled and difficult, people represented values in an abstract manner, advancing from barter system through certified notes of money, checks, payment orders, debit and credit cards, and nowadays online payment (or electronic payment) systems. Some well-known issues or defects are found in the customary methods of payment: cash can be falsified, cheques bounced, and signatures forged. Contrary to this, appropriately planned electronic system of payment can really give ideal security over conventional methods of payments, with the added advantage of pliability in usage [4][5]. The ease of making monetary exchanges and additionally a more secure and faster access to capital resources, among different other components, has put online payment system on a celebrated stride than the cash currency based system [6][7][8]. With intangible transactions becoming more impactful in overall economies and their prompt transference at little cost, conventional systems of payment have a tendency to be more expensive than the present-day strategies. Furthermore, processing on the internet can be of less worth than the smallest estimation of cash in the manual world [9].

With the immense participation of the web in our everyday life, individuals feel accustomed to online exchange in ECommerce for selling and purchasing of products and ventures. People are paying cash electronically over the Internet [10]. Moreover, the rise of web-based business has led to new money-related necessities that by and large can't be viably satisfied by the customary methods of payment. Following to this growing trend, related individuals are investigating different online systems of payment including issues encompassing the online system of payment and digitised 
currency [5]. Every single transaction that takes place online is made via payment gateways which act as points at which the financial organisations can be accessed. Payment gateways authorise and validate details of payment between different parties and the various financial organisations [10].

This paper gives a comprehensive description aimed at increasing awareness about the development of online payment systems. The remaining paper is organised as: A number of definitions of online payment systems, their history and other related aspects have been provided in Section 2. Section 3 discusses the online payment gateway model and the comparison of various payment systems available online. The developments in online payment system together with its adoption have been given in Section 4. Section 5 and 6 present the various advantages and issues associated with online payment systems. The elucidations of its various security requirements and future considerations have been given in Section 7 and Section 8, respectively. Finally, the paper is concluded in Section 9.

\section{ONLINE PAYMENT SYSTEM}

As exchanges among different partners of business keep on proffering on the e-commerce platform, the previous cashbased system of payment was slowly replaced by the electronic payment systems [11]. The appearance of this advancement in the worldwide business platform prompted most business establishments to naturally change from the customary paperbased cash exchanges to an electronic system of payment which is generally known as the online payment system or epayment system. By and large, these electronic systems can be seen as a method of making payments for merchandise or services which have been established online using the internet [12] [13].

An Electronic Payment System or online payment system can be defined as a type of inter-organisational information system (IOS) for money related transactions, connecting numerous associations and individual clients. A need of complex interactions may be required among the partners, the environment and the technology. The exclusive attributes of EPS/IOS also separate it from the conventional internal based systems of information; technologically, relationally and organisationally, it is more intricate and complicated [14][15][16], highlighting the significance of cooperation and the need to unite all aspects together [17].

Notably, the global annual non-cash transactions facilitated by online payment and mobile payment (m-payment) had been on the upsurge over the years, except for 2012 where it decelerates from an annual growth rate of $8.6 \%$ in 2011 down to $7.7 \%$ in 2012 [18]. Furthermore, in 2014, volumes of worldwide non-paper exchange went up to $8.9 \%$ reaching 387.3 billion, the most noteworthy development rate since the first publication of World Payments Report. The growth was chiefly determined by quickened development in newly forming markets. The higher worldwide development is anticipated to have kept up in 2015, with assessments of a development rate of $10.1 \%$ which will make the non-paper exchange volume reach 426,300,000,000 [19]. Online payment systems are important mechanisms used by individual and organisations as a secure and convenient way of making payments over the internet and at the same time a gateway to technological advancement in the field of world economy [20]. In addition, it has also become the major facilitating engine in e-commerce through which electronic business success relied upon. Online electronic systems of payment had likewise realised proficiency, reduced rate of frauds and resourcefulness in the systems of world payment [13][21].

\section{A. What is an Online Payment System?}

The online payment system is a comprehensive term, portraying various scopes of delivery through electronic multichannel. Its use for various purposes offers an amplified imprecision of characterising online payment in literature. Online payment can be seen from its capacities as e-banking, m-payment, e-cash, internet banking, online banking, ebroking, e-finance and so on. All things considered, recent researchers have demonstrated a few endeavours to come up with a definition of online payment [8].

Dennis (2004), characterises the system of online or electronic payment as a type of financial commitment that includes the purchaser and the vendor enabled by the utilisation of electronic infrastructures [11]. Additionally, Briggs and Brooks (2011) views online payment as a type of inter-relation amongst associations and people helped by banks and interswitch houses that empowers financial transaction electronically [17].

Another point of view is put forward by Peter and Babatunde (2012) who see online payment system as any type of money exchange through the internet [22]. On a similar note, as indicated by Adeoti and Osotimehin (2012), a system of online payment alludes to an electronic method for making payments for merchandise obtained on the web or in markets and shopping centres [23]. Another definition suggests that online payment systems are payments made in electronic exchange conditions as exchange of money via electronic means [24].

Besides, Kalakota and Whinston (1997) view online or electronic payment as an exchange of money that happens online between the merchant and the purchaser [25]. In addition, Humphrey and Hancock (1997) are of the view that online payments allude to money and related exchanges actualised utilising means of electronics [26]. Online payment is also defined as payment by means of electronic exchange of details of credit cards, direct credit or some other electronic means other than payment with money and cheque [27].

Antwi et al. (2015) characterised online payment as an exchange of a fiscal claim by the payer on a party worthy to be useful [28]. Lin and Nguyen (2001) define online payment as payments made via the automated clearing house, commercial card systems and electronic transfers [29]. Shon and Swatman (1998) characterise online payment as any trade of money started by means of an electronic correspondence channel [30]. Gans and Scheelings (1999), define online payment as payments made by the use of electronic signals connected debit or credit accounts [31]. Hord (2005) observes online payment as any sort of non-money payment that does not include a paper cheque [32]. 
Likewise, Teoh et al. (2013) saw online payment as any exchange of an electronic worth of payment from the buyer to the seller by means of an online payment channel that permits clients to remotely access and deal with their financial accounts and exchanges over an electronic system [33].

In general, an online payment system is an arrangement of monetary exchange amongst purchasers and vendors on online conditions that is helped by a digital financial instrument, (for example, electronic checks, encoded credit card numbers, or cash in digital form) supported by a bank, a mediator, or by a lawful associate [34].

\section{B. Historical Background}

The history of online payment can be traced back to 1918 the time when currency was first moved in the United States (U.S.) by the Federal Reserve Bank with the aid of telegraph. However, that technology had not been widely used in the US until the time when their Automated Clearing House (ACH) was incorporated in 1972. Since that time, the electronic money turned out to be quite popular. This enabled U.S. commercial banks and its central treasury came out with an alternative to cheque payment [13].

Credit card industry can also be traced back to 1914 when department stores, oil companies, Western Union and hotels started issuing cards to their customers to enable them to pay for goods and services. After about 40 years of credit card evolution, there have been increasing numbers of credit card usage as they have become more acceptable by people as a medium of payment, especially in transportation. Initially, credit cards were all paper-based payments, until in the 1990s when such cards were transformed to electronic completely. Due to the increasing number of credit card usage, the industry has grown rapidly which lead to the introduction of a debit card too. Debit and credit cards are now used in transaction payments for all types of purchases or services rendered all over the world [13][35].

With the evolution of e-commerce and technological advancement, electronic cashless payments are now used conventionally even though having being set in the 1960s [36]. The research community has made relentless efforts resulting in the development of various online payment models like the $\mathrm{N}$. Asokan model and the JW model. In the JW model - a conventional payment system, sellers as well as buyers require some kind of involvement for carrying out a specific transaction [37]. The N. Asokan model was launched in 1998 and involves the participation of a bank besides the seller or buyer in transaction processing lest one of them is missing in any transaction [38]. Another model viz. 3e model that is built on the N. Asokan model includes electronic cheque, electronic cash and credit card payment models [37], the most popular being the credit card mode of payment [39].

The concept of transferring funds electronically using the Internet progressed with the aim to transfer money instantaneously among peers. For supporting this goal, several possible solutions have been proposed such as ATM networks and wire transfer. In order to carry out money transfers internationally, various fast and popular frameworks have been given. Crypto currencies such as Litecoin and Bitcoin can be used for transferring money to anybody in the entire world within no time; however, the wallet holder's identity and the Bitcoin transactions are not monitored by any central organisation. So, Bitcoins can be used by scammers for their illegal pursuits on the Internet. Now, the popularity of operating systems like iOS and Android has also grown in the recent years. With the concept of mobile banking and mobile wallets, peer to peer transferring of money has moved to a higher stage of development since it made possible services like ticket booking, peer-to-peer (P2P) money transfer, bill payment, mobile recharges and money withdrawals [40]. The earliest mobile banking service dates back to 1977 when Merita Bank in Finland used an SMS - short message service [41] for allowing people an easy and fast access to their facilities; it has been witnessed that mobile phones are used by $50 \%$ people but mobile banking is accessed by $37 \%$ only [42]. The advantages and need of mobile banking has been studied by researchers [43]. Many finance companies provide smartphone applications that allow users to pay anybody, anytime and anywhere. However, with continuous use, hackers found them as an easy prey and were successful in performing fraudulent transactions. Furthermore, a stretchable and ultrathin stamp is now available which users wear on the skin and can be employed for payment while being connected to a smart-phone [44] [45].

\section{Classification of OnlinePayment Systems}

There are quite a number of online payment services that have been developed within the payment system around the globe. These include electronic cheques, e-cash, credit cards and electronic fund transfers [13][46].

Several types of online payment systems have been studied by [47] who classified them into electronic currency and account-based systems. In account-based systems, users are allowed to pay using their own bank accounts while the latter allows consumers to pay only with the help of some electronic currency. Both the systems provide numerous payment methods such as i) Electronic payment cards (credit/debit and charge cards), ii) Mobile payments, iii) E-wallets, iv) Smart and loyalty cards, v) Virtual credit cards, vi) Stored value card payment, and vii) E-cash

On evaluation of the online payments systems by [48], several features of varied online payment methods have been accentuated as:

\section{1) Credit Cards}

Credit cards are by far the most popular mode of online payment. In the beginning, security concerns hampered their adoption but gained customer trust later when security features were provided for each transaction. Credit card applicability is one of the strongest factors which contribute to its extensive use all over the world. Nonetheless, it is not considered feasible for making small payments or small businesses since they require huge fees [48]. The most important advantage of credit cards is the ease-of-use they provide in performing transactions online from any part of the world and in no time. Moreover, they can be obtained easily without the burden to possess any additional hardware or software for making them work. The authentication of card-holder is simply provided using credit card number, a name and expiry date. In order to keep the 
personal information of users secure, complementary systems, like Verified by Visa and MasterCard SecureCode have been developed by credit card companies. Moreover, this payment mode offers users with the provision of password creation which they use for shopping online via credit cards.

\section{2) Debit Cards}

Debit cards are gaining popularity with each passing day and have become the most popular cashless payment methods all over the world [49]. As compared to credit cards, the payments made via debit cards are withdrawn from the consumer's personal bank account and not from any intermediary account. So, users fail to have an additional security in their debit accounts thereby troubling them while handling payment disputes. However, only the account number is required for making debit payments with no need to produce a card number or a physical card. Although debit cards have a huge user base in several countries but they are not widely used on merchant websites due to their failure to satisfy international customers [48]. The costs incurred by the usage of debit cards are lower as compared to credit cards which makes them feasible for micropayments. Furthermore, they have a higher level of security than credit cards due to the requirement of extensive identifications demanded by banks.

\section{3) Mobile Payments}

As per [50], the payments that are made via wireless devices such as smart-phones and mobile phones are assumed to offer reduction in transaction fees, and increase in online payment security and convenience. Such a payment method has facilitated businesses in the collection of valuable information regarding their customers as well as their purchases. According to [48], mobile payment systems are applicable globally as a result of their astonishing growth and downright incursion of mobile devices in comparison to other telecommunication infrastructure.

Mobile payments have been found to be feasibly used for both online purchases and offline micropayments. Since the mobile phones have a huge consumer base, online traders are potentially attracted to this payment method. The usage of mobile payment services reduces the overall transaction costs as well as provides a better security [50]. Nonetheless, their inability to suffice international payments and privacy has led to several issues in gaining a significant user base.

\section{4) Mobile Wallets}

According to Doan (2014), "Mobile wallet is formed when your smartphone functions as a leather wallet: it can have digital coupons, digital money (transactions), digital cards, and digital receipts" [51]. Using mobile wallets, users are allowed to install the application in their smart-phones which they can employ for making offline as well as online purchases. In future, mobile wallets are assumed to offer more convenience to customers in making transactions with the help of technologies which connect smart-phones and the physical world via sound waves, cloud-based solutions, NFC (Near Field Communication), QR codes, etc. [52].

\section{5) Electronic Cash}

In the initial phase of online payment system introduction, electronic cash systems by the name CyberCash or DigiCash were proposed. Nevertheless, those payment systems disappeared soon as they were not appreciated much. Currently, systems based on smart card are more commonly used by businesses for paying small amounts. But smart cards are dependent on card reader and particular hardware for their authentication and use. Besides smart cards, a large number of electronic cash systems like Clic-e and Virtual BBVA have also been set up. Electronic tokens or prepaid cards are employed by these systems which represent some specific value and can be bartered for hard cash [48] [76].

Since 2010, the cards as instruments of payment have shown fastest growth, which is evident from the fact that the use of cheques has declined in the last 13 years. Debit cards stand out among the other types of payment instruments and accounts for the highest share $(45.7 \%)$ of worldwide non-cash money exchanges and have proved to be the fastest growing $(12.8 \%)$ instruments of payment in the year 2014. These statistics allude to the fact that the security and convenience provided by the cards in comparison to other instruments of payment and the compatibility with the newcomers to build innovative series because of their easy payment infrastructure [19].

Furthermore, the electronic mode of payment can be accomplished in a mobile environment as well. Various Android applications in smart-phones like Ngpay, Paytm provide an online service of payment. In case of the online payment system, these mobile applications work equally to a Desktop computer. There are other ways in which clients employ their mobile phones for paying their transactions. By making use of the mobile internet, customers may transmit a PIN number, send an SMS message or utilise WAP to pay electronically over the internet. For online payment, the vendors can authenticate a particular client's debit or credit card transaction by assigning an instrument to their mobile phones. In the United States, a conglomerate of late publicised Power Swipe, which is physically connected to a Nextel telephone, has a weight of 3.1 ounces, and involves a reader for magnetic stripe, goes through connector for charging the battery of the handset, and an infrared port for printing [53].

\section{ONLINE PAYMENT GATEWAY MODEL}

In today's world, online shopping has become popular; the utilisation of online payment provides a large number of advantages to vendors as well as clients. For processing, the transactions that take place over the web must go through a payment gateway. In practice, the payment gateways act as a link amongst financial organisations responsible for conducting the money exchange and the vendor's website [54].

In business over the Internet, different factions are included in the online payment process (as shown in Figure 1) for selling and purchasing products. An electronic Payment Gateway is a fundamental part for online transactions and supposed to ensure the client that exchange is reliable and safe in every aspect of security [10].

An E-Commerce Payment Gateway is a basic part of infrastructure to guarantee that such exchanges happen with no problems and the overall security over electronic systems is maintained. A Payment Gateway acts as an access point to the 
national banking system. Every single online exchange must go through a Payment Gateway to be handled. A Payment Gateway routes and confirms details of payment in amazingly secure conditions between related banks and different factions. The Payment Gateway works basically as an "encoded" channel, which safely routes details of transactions from the purchaser's Personal Computer (PC) to banks for authentication and countersignature. Upon approval, the Payment Gateway sends back the data to the merchant consequently finishing the "order", and giving confirmation [55].
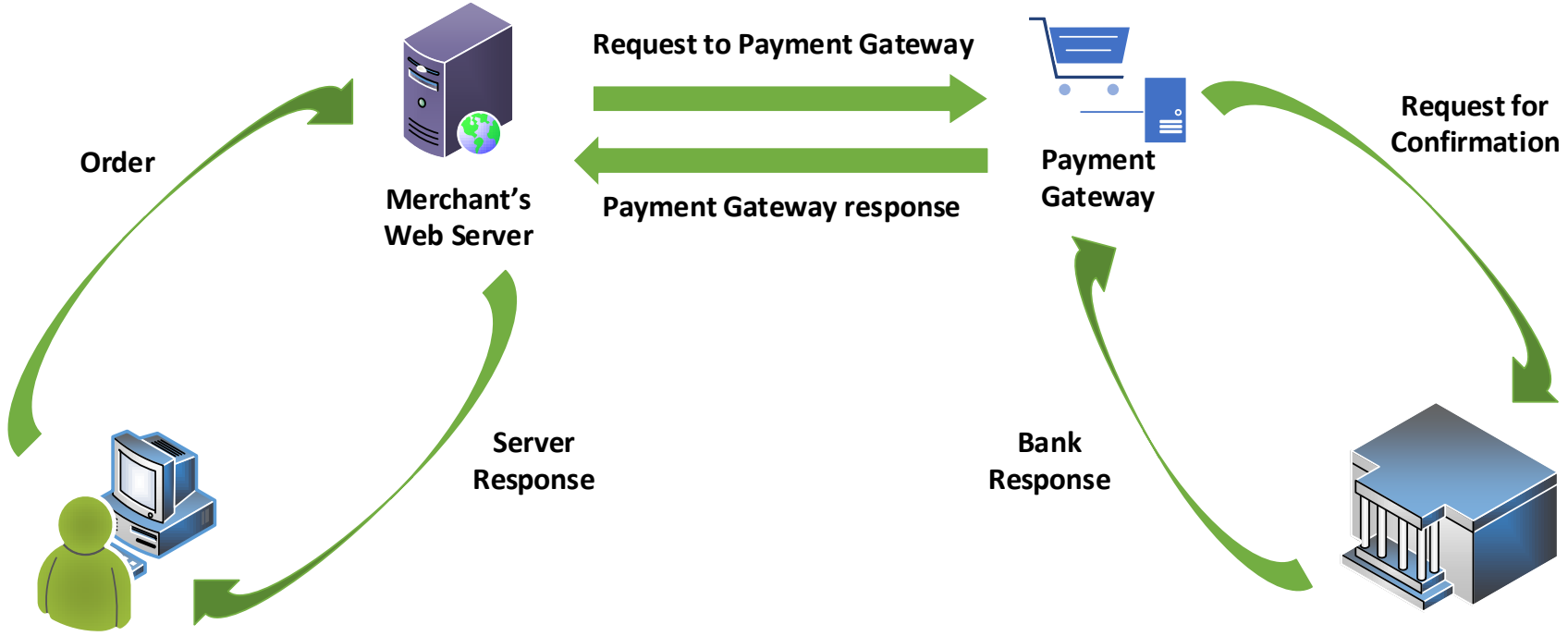

Payment Gateway response

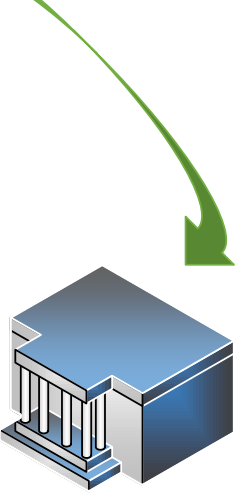

Bank

\section{User placing order}

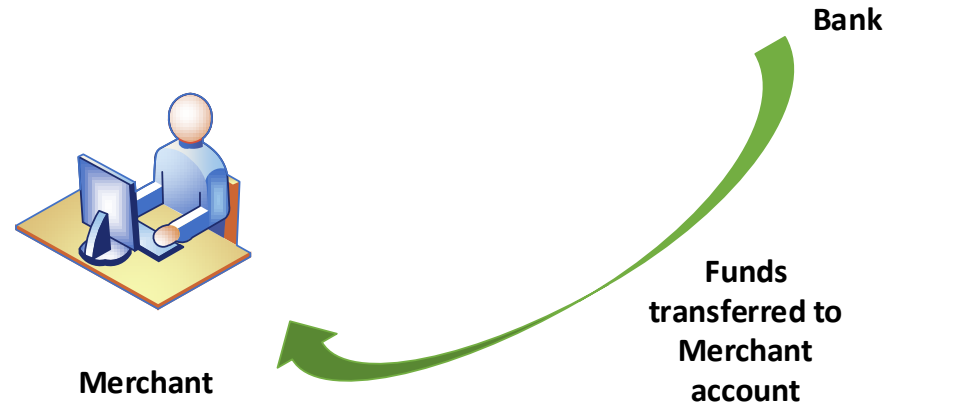

Fig. 1. Online Payment Process

\section{A. Popularly Used Online Payment Systems}

One of the best apparatus that the Internet offers in today's world is the ability to shift one's business wherever they want by means of a website. This is the reason it became noticeably vital to buy by means of the Internet through numerous payment service providers. Payment Service Provider is an organisation that offers online services related to marketing; it recognises online payments by overseeing exchanges amongst vender and purchaser. The most well-known payment techniques that are typically provided are by bank transfer, real time orders and credit card.

Some popular systems of online payments are [56]: (1) Braintree, (2) Stripe, (3) PayPal, (4) Authorize.Net, (5) 2CheckOut, (6) Dwolla, (7) Worldpay, (8) Eway, (9) Samurai, by Feefighters, (10) Serve, from American Express, (11) Intuit GoPayment, (12) Icepay, (13) Amazon Payments, (14) Skrill (before Moneybookers), (15) WePay, (16) V.me by Visa, (17) Square, and (18) Google Wallet/ Google Checkout.

\section{B. Comparison of Payment Gateways}

When making a choice for a payment gateway, the main considerations that should be considered are as following: card types, transaction fees, recurring bills and form payments. These elements will fluctuate accordingly with the processor, so it must be guaranteed that payment gateway selected has to be in accordance with the needs and budget of the client [57].

By making a comparative investigation of payment gateways, different services and criteria are described below. Each one of these payment gateways concentrate on various elements such as currencies, cost, security, support, features, etc. These appear underneath in a tabulated form as given in Table 1. 
TABLE I. DIFFERENT FACTORS OF COMPARISON FOR PAYMENT GATEWAYS

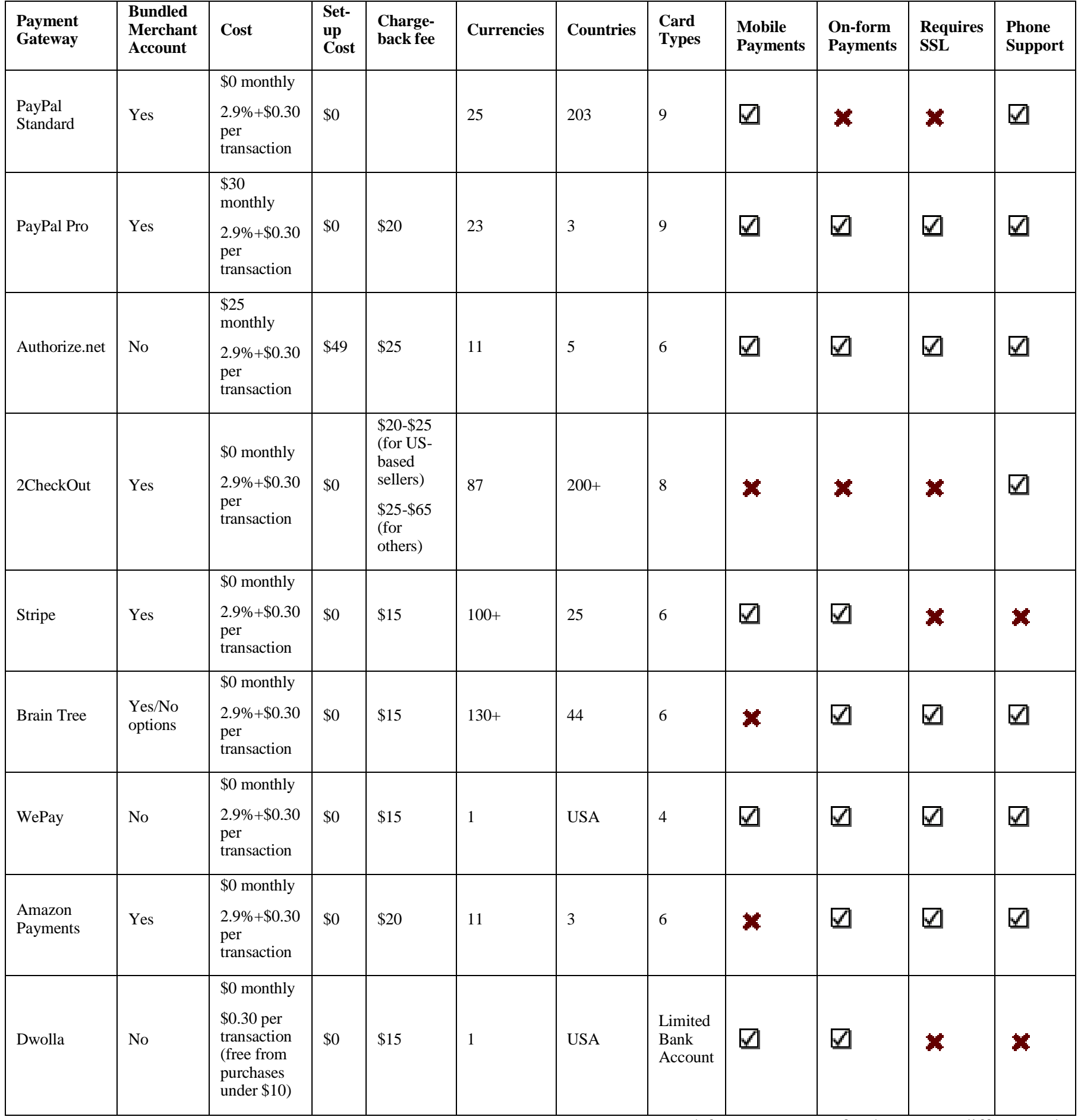

\section{ONLINE PAYMENT SYSTEM DEVELOPMENTS}

Globalisation in today's world is the result of innovative technological endeavours. The advancement in technology has changed the skyline of payment systems, moving towards eWorld [58]. Decisively, current innovation has changed customary systems of payment into a more proficient and viable system, which is free from the cash-and-carry disorder. The effectiveness of executing financial transactions and also a more secure and faster access to funds, among different other components, has put e-payment system on a more celebrated pace than the paper money based framework [6][7]. Interestingly, in Nigeria, online payment framework is picking up eminence to the degree that clients have now wanted to do financial transactions without going to the banks. Thus, time of money based payment framework is slowly blurring out as the cashless economy dominates present day financial systems [59][60]. Lately, online payment system has turned into a 
standard through which fiscal element moves advantageously, particularly in a developing country like Nigeria where it is habitual to carry cash. In such a country, the online payment system has shaped into an important starting point of her present-day economy; a well-working system of online payment has been perceived to have much pertinence to budgetary strength, overall financial activity, and monetary policy [8]. In the meantime, the initiative for an economy that is not based on cash will be preferred in the new era only when it is supported with age advantage, good education, ownership of important innovative foundations, among different other components, appropriately set up by every concerned individual of the economic system and proficiently managed before forcing the citizens to comply.

A number of researches were done on the systems of online payment and development of economy in the current time. Newstead (2012) inspected cashless systems of payment and monetary development and found a connection between cashless payment and the pace of financial development. The review discovered that cashless payment volumes are developing twice as quick in the developing countries as they are over the world [61]. Likewise, World Payments Reports (2012) investigated the state and advancement of worldwide non-paper money systems and discovered non-cash payments make it less demanding and speedier for individuals and organisations to purchase products and enterprises, thrusting cash into the framework quicker and adding to the GDP [62]. The conclusion of the review was like that of Hasan et al. (2012) who investigated principal connection between online retail payment and general financial development utilising information from over 27 European nations from 1995 to 2009 and came to know that relocation to proficient electronic retail payment empowers general financial development, utilisation and exchange [8][63].

Apart from the safety and convenience, online payment systems additionally have a significant number of financial advantages [64]. Their chief financial advantage involves mobilising investment funds and guaranteeing a large portion of the cash accessible to the nation and with the banks, making funds accessible to borrowers (organisations and people). Moreover, an online system of payment can track spending of a particular individual; to simplify the framework of services offered by the banks. This data is likewise helpful to the administration when settling on financial adoptions. Online payment system likewise can diminish the cost on money handling and costs on printing. As per (Moody's Analytics, 2010), genuine worldwide GDP on an average increased by an additional $0.2 \%$ per year considered to what it would have been without the utilisation of cards. Basically, the use of cards develops a nation's GDP by $0.2 \%$ every year [64].
In a society where $90 \%$ of money is held outside of the banks to migrate to a cashless economy is a major transformation. It is subsequently a gigantic test for the government, money related establishments, people and different other partners in charge of making this framework accomplish its financial advantages [65]. There are probably going to be economic, operational, financial and advertising changes that should be overseen in a proper manner.

Conventional techniques of payment incorporate bank exchanges, debit cards, and credit cards. In 2014, the quantity of cards with a function of payment improved up to 766 million in the EU. The measure of exchanges by means of cards was 47.5 billion, with an aggregate estimation of 2.4 trillion dollars. However, individuals incline towards other choices or local solutions of payment. The scene of optional payments has advanced and is believed to assert $55 \%$ of eCommerce revenue by 2019, as described in Figure 2 [66].

The payments industry all over the world is growing at a fast pace with the filtering of investments by big banks and the development of emerging technologies by progressing startups. It was reported by Boston Consulting Group [67] in 2016 that the transaction banking may reach from $\$ 1.1$ trillion in the year 2014 up to $\$ 2$ trillion in the year 2024, as depicted in Figure 3. While the focus has been on technology and innovation, the advantages of new payment mechanisms are now being realised by businesses for improving the bottom line and fuelling corporate growth.

As per Vaughan Rowsell [67], chief product officer and founder at Vend, "Popular businesses are showing others that those payment solutions, which were new a few years ago, like contactless cards or mobile wallets, are now real, reliable and widely used. As adoption has been slow, but steady, the technology has been able to evolve and become better over time." Furthermore, he also says that a lesson that businesses can take from this is the revelation of the number of choices available to the user as the largest element of bottom line growth. The greater number of user payment options, cheaper and quicker systems imply that there is reduced dependence on cash. Nevertheless, it also implies that the expectations of customers are growing.

Global Payments UK managing director and president, Nigel Hyslop [67] quotes: "We have seen a sharp increase in the number of people using their mobile phone to make purchases online or pay with contactless for items up to $£ 30$." Furthermore, he also says: "More people are realising that using contactless with their mobile is easier than digging around for spare change when paying for lower-cost items." 


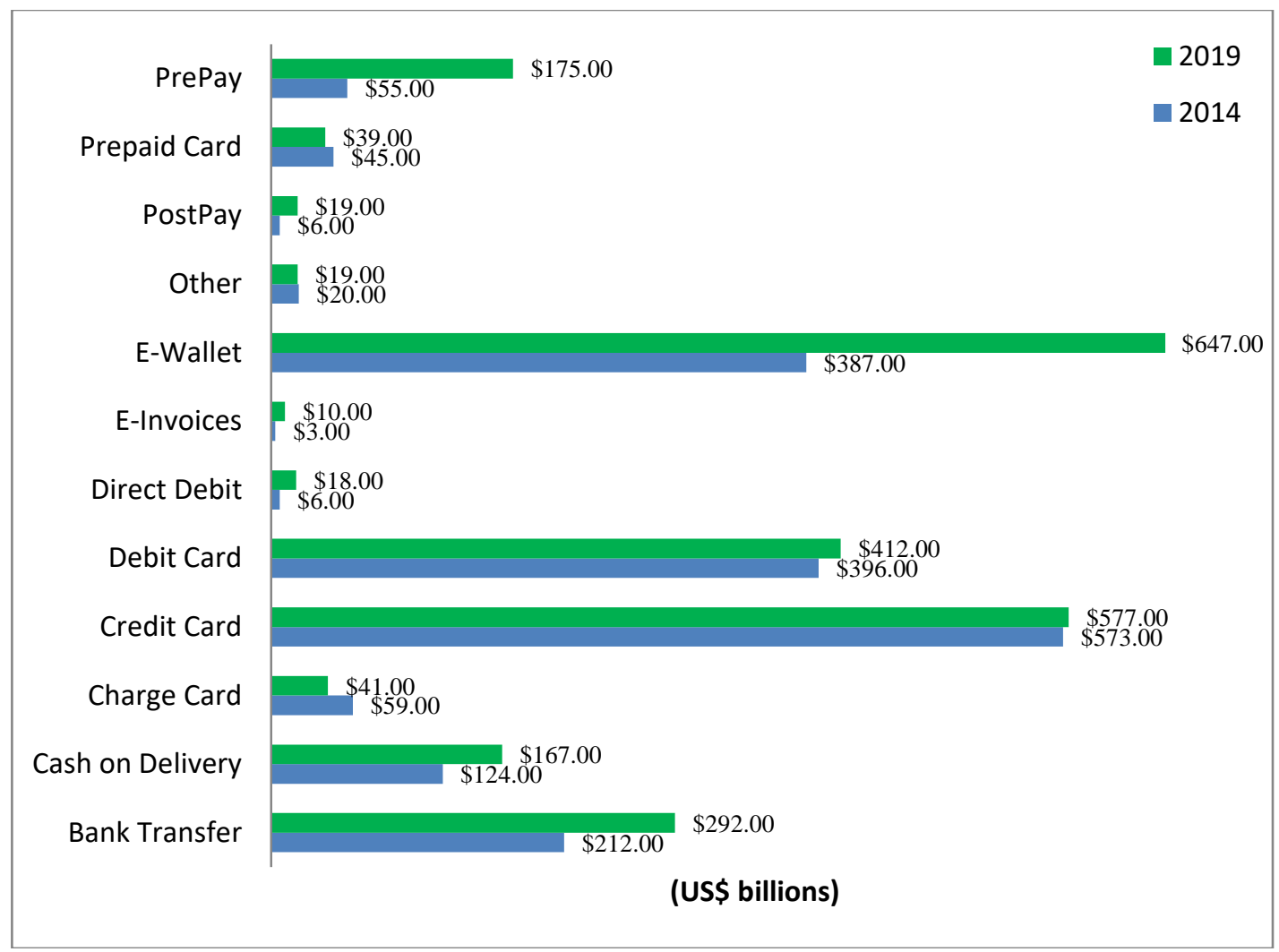

Fig. 2. Future Trends of Payment Methods [Source: Global payments report preview, Worldpay, November 2015]

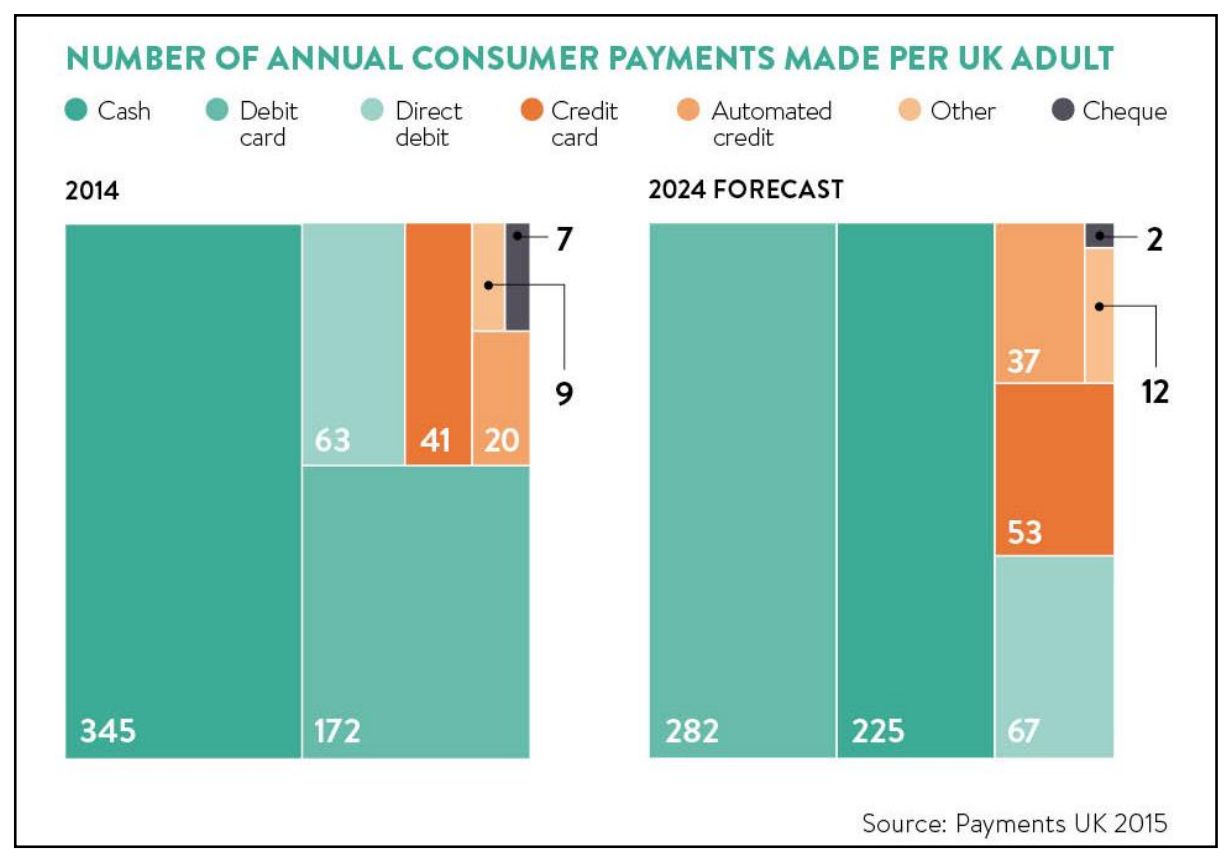

Fig. 3. Annual Consumer Payments 2024 Forecast

In the former years, the adoption of contactless systems of payment has grown by a large scale at the physical point-ofsale (POS). As per the reports of UK Cards Association [67], there was an increase in the total contactless transactions made in the month of January 2016 by $212 \%$ as compared to the transactions made in January 2015. Such a trend has been driven by banks that continue issuing contactless enabled cards followed by the continuous activation of compatible POS terminals by retailers in order to benefit from the reduced acceptance costs of contactless mode of payment.

New methods of payment are now being used by some of the leading businesses in the world and are thus moving one step ahead than making payment for goods. Rather, they are 
being used for enhancing the interaction of buyers with the company's products. At the onset of the month of April 2016, SWIFT banking cooperative made an announcement which said that an innovative global payment initiative was signed by 21 banks for improving the user experience with an increased transparency, predictability and speed of cross-border payments. The banks that had participated include leading banks like Bank of China, Wells Fargo, Bank of America Merrill Lynch, J.P. Morgan Chase, Barclays and Royal Bank of Canada [67].

Despite the enormous development of payment technologies, the customer acceptance has not been found to be satisfactory. In this regard, various factors have been underlined as being responsible for the adoption of mobile wallets successfully in the market. According to a survey report, about 62 per cent people are apprehensive about their system security. As per the reports of another survey that was made in the year 2015, among the existing systems of customer digital payment, 16 per cent customers gave preference to digital payment however 67 per cent customers are partial to cash even now. Furthermore, the acceptance rate of debit cards was found to be 59 per cent while 50 per cent customers relied on credit cards. The contactless payment technologies are also seen to have lesser excitement among customers where only 5 to 6 per cent consumers believe that they would be using digital mode of payment by the year 2020 [68] [45]. The rates of acceptance of traditional as well as digital modes of payment have been given in Figures 4 and 5, respectively. people preferring this payment mode followed by credit cards opted by 35 per cent people [69]. Since customers find more comfort in the use of credit or debit cards, these payment cards have been digitised by several companies by incorporating many of them in one product, e.g., Plastic cards, Coin and Stratos can store up to 20 cards, 8 cards and 3 cards respectively whereas a whopping 25 cards can be loaded by SWYP [70].

One of the main barriers to customer acceptance has been found to be security as stated by 45 per cent respondents who were surveyed. The most important reason behind this is assumed to be the resistance of customers to switch technologies; about 97 per cent customers showed repudiation in buying a new device which supported mobile payments [71]. As per a survey conducted in the year 2016, people were found to be less likely to use mobile payment with only 6 per cent ready to make use of a mobile payment app [72]. The major issue that has been found to be associated with mobile payment mode is the high cost of smart-phones that these payments rely on, particularly in countries where they can be afforded by few people only. India has been observed to be the second largest smart-phone market with an estimated 73 per cent people using mobile phones all over the country. Owing to the technological innovations, about 40 per cent users of smart phones in India possess a mobile wallet [73]. Moreover, it was also reported that 74 per cent people intend to make use of a mobile wallet in the emerging markets whereas this figure goes down to mere 46 per cent in the developed markets [73] [45].

According to a survey on payment technologies, it has been found that debit cards are the most popular with 43 per cent

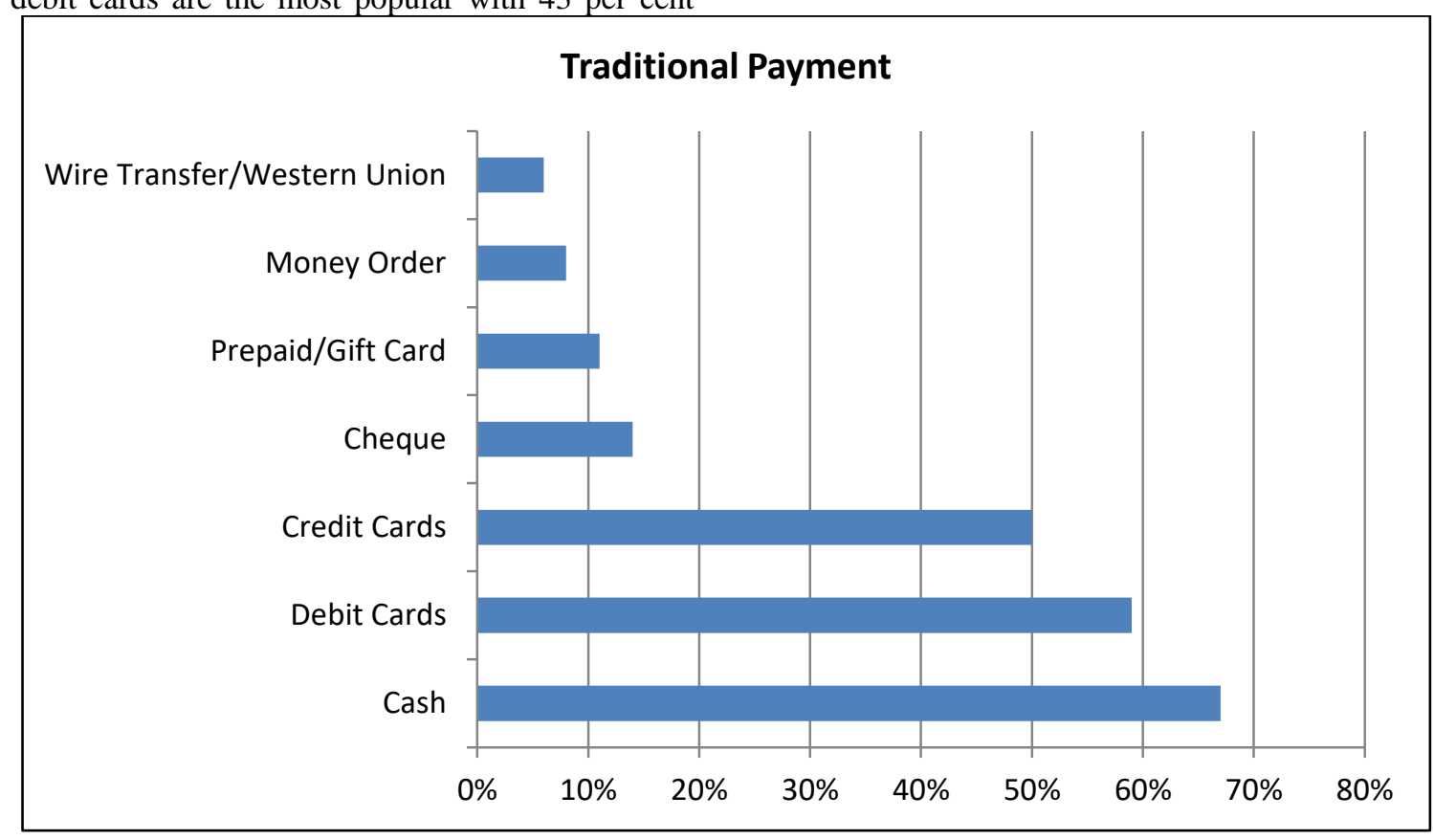

Fig. 4. Acceptance Rates of Various Traditional Payment Systems 


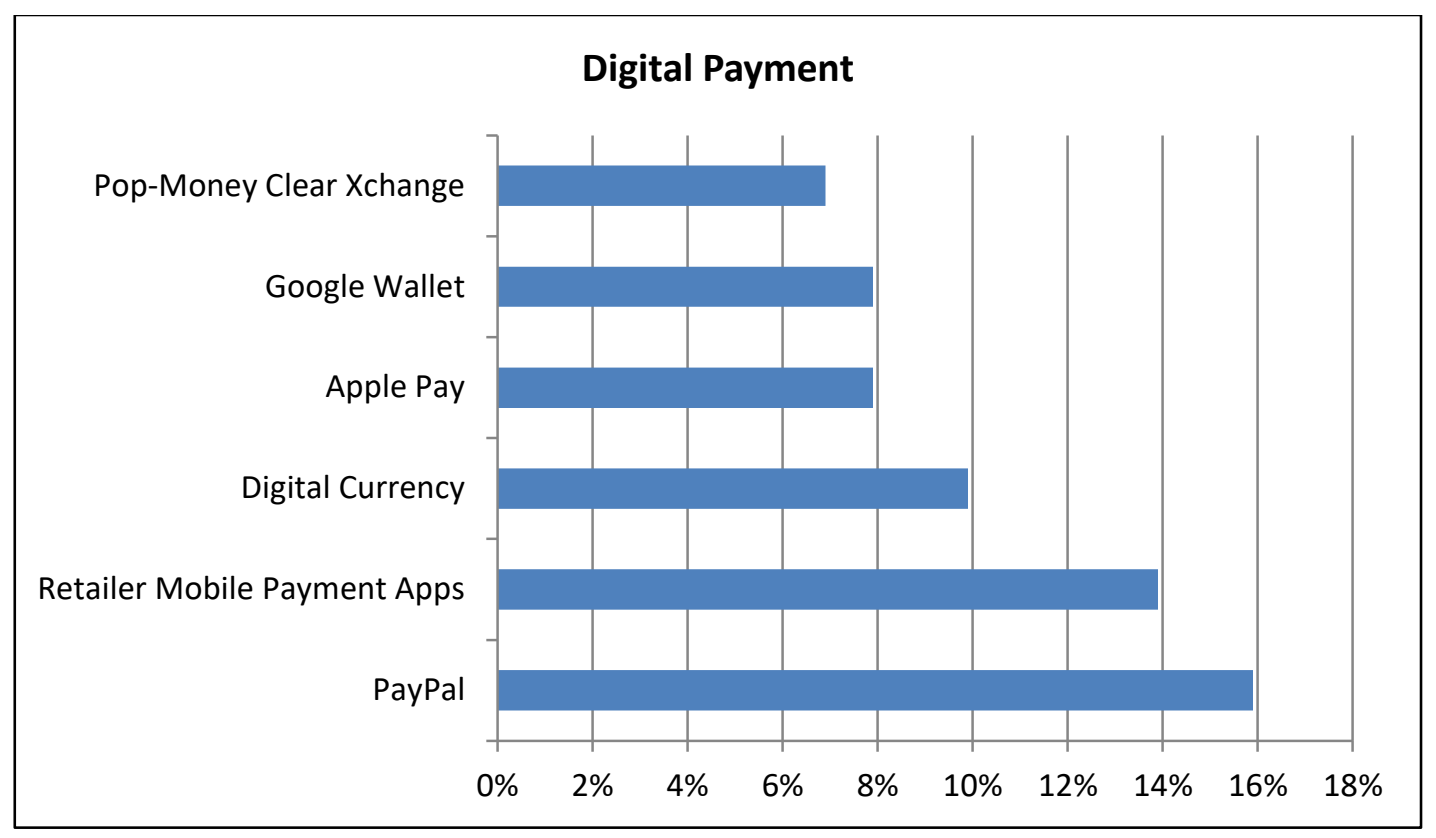

Fig. 5. Acceptance Rates of Various Digital Payment Systems

\section{ONLINE PAYMENT SYSTEM AS A BOON}

For the first time in history, a review by the Federal Reserve Financial Services Policy Committee shows that electronic payment exchanges in the United States have surpassed cheque payments. In 2003, the total number of electronic exchanges were equivalent to 44.5 billion dollars, while the quantity of cheques paid were equal to 36.7 billion dollars. Evidently, a pattern among buyers can be recognised; purchasers are seen to be more willing to work with online electronic transactions and employing an automated medium to do their businesses.

As indicated in a review by Fiallos and $\mathrm{Wu}$ (2005), the ingress of the web has put electronic payments and exchanges on an exponential development rate [74]. Customers could buy merchandise from the web and send credit card numbers in an unencrypted form over the system, which made the transactions quite vulnerable to threats and frauds. With development in online payment systems, a wide assortment of new secure systems of payments have come up as customers turned out to be more mindful of their protection and security. As argued by Cobb (2005), Online Payments have remarkable number of financial benefits in addition to their safety and ease of operation. These advantages when expanded can go far in contributing hugely to financial improvement of a country [75].

Computerised electronic payments help develop deposits in banks and in this manner, increase reserves accessible for business credits - which is considered as a driver of financial achievement. As per [75], advantageous and secure electronic payments convey with them a noteworthy scope of full scale financial advantages. "The impact of introducing online payments is akin to using the gears on a bicycle. Add an efficient electronic payments system to an economy, and you kick it into a higher gear. Add better-controlled consumer and business credit, and you notch up economic velocity even further".
Online payment system can be helpful in uprooting shadow economies, bringing masked exchanges into the banking system and help in bringing straightforwardness, cooperation, and confidence in the economic system. In addition to this, as specified by Al Shaikh (2005) in [75], there is a relationship between the rise in demand deposits and increase in point of sales volumes. "Automated electronic payments act as a gateway into the banking sector and as a powerful engine for growth. Such payments draw cash out of circulation and into the bank accounts, providing low cost funds that can be used to support bank lending for investment - a driver of overall economic activity. The process creates greater transparency and accountability, leading to greater efficiency and better economic performance".

In a comparative account in [76], online payment is extremely helpful for the buyer. Most of the time, the user is required to enter his account related information - for example, credit card number and delivering address - once. The data is then kept on retailer's web server's database. When the client returns to the webpage, he simply signs in with his username and password. "Completing a transaction is as simple as clicking your mouse: All you have to do is confirm your purchase and you're done".

Hord (2005) in [76] additionally underlines that online payments bring down expenses of organisations. Less cash is spent on paper and postage with increasing number of online payments. Presenting the option of online payments can likewise help organisations enhance client preservation. "A customer is more likely to return to the same e-commerce site where his or her information has already been entered and stored".

As indicated by [75], "Electronic payments can thus lower transaction costs stimulate higher consumption and GDP, increase government efficiency, boost financial intermediation and improve financial transparency". The author additionally 
states, "Governments play a critically important role in creating an environment in which these benefits can be achieved in a way consistent with their own economic development plans".

Humphrey et al., 2001 likewise bolster the reality that utilisation of online payment systems holds the guarantee of tremendous advantage to both vendors and buyers as costs are reduced, more ease of use and higher security, dependable means of payment and settlement for a possibly immeasurable scope of products and enterprises offered worldwide over the web or other electronic systems [77]. One such advantage is that online payment systems empower bank clients to deal with their everyday money related transactions without visiting their nearby bank office. Online payments could save dealer's time and cost in taking care of money [78].

As signified in [79], the asset cost of the payment framework of a country can represent $3 \%$ of its GDP. Since most online payment systems cost just around $33 \%$ to $50 \%$ of the paper-based non-money payment, clearly the social cost of a payment framework could be impressively lessened if it is computerised [78]. Mechanising and reshuffling electronic payments produced using self-serve channels, for example, ATMs, point-of-sale (POS) systems, and branch office terminals can lessen paper-based mistakes and expenses.

An examination work completed by Visa Canada Association as a team with Global Insight (A main monetary and budgetary counselling firm) discovered that online payment systems give proficiency in transactions to purchasers, traders, banks and on the whole the economy. Online payments have contributed \$C 107 billion to the Canadian economy since 1983 and comprise of about $25 \%$ of the \$C 437 billion aggregate development in the Canadian economy over the said period. Over the same two decades, \$C 60 billion of the expansion in Personal Consumption Expenditures was specifically inferable from online payments, with credit card having a major share in this development $(\$ C$ 49.4 billion) in comparison to debit cards (\$C 10.4 billion) [80].

\section{Online PAYMEnT System AS A Challenge}

In spite of the numerous advantages of the online payment systems, they have their own difficulties and challenges even in today's technologically advanced world. The challenges which have been identified by previous researchers are Infrastructure, Regulatory, Legal issues and Socio-Cultural issues.

\section{1) Infrastructure}

Infrastructure is fundamental for the effective execution of online payments. Appropriate infrastructure for online payments is an issue [81]. For online payments to be fruitful, it is necessarily required to have a financially savvy and reliable infrastructure that can be availed by dominant part of the populace. In developing nations, large portions of the country don't have banks and have no access to basic infrastructure that drives online payments. In connection to this, a research work by Mishra (2008) reveals that in Nepal, Electricity and Telecommunication are not accessible all through the nation, which contrarily influences the advancement of online payments [82].

\section{2) Regulatory and Legal Issues}

National, provincial or global arrangement of laws, standards and different other directions are imperative prerequisites for the effective execution of online payment plans. A significant portion of components incorporate guidelines on tax evasion, supervision of e-money organisations and commercial banks by supervisory specialists; central banks should keep an oversight on payment systems, buyer and information protection, participation and rivalry issues. As indicated by Taddesse and Kidan (2005) the worldwide and virtual nature of online payment additionally brings up legal issues, for example, which laws are relevant in debated cases and which jurisdiction will be competent, legitimacy of digital signatures and electronic contracts [81]. A legitimate and administrative structure that builds confidence and trust helping technical endeavours is a vital issue to be tended to in executing online payments.

\section{3) Socio-cultural Challenges}

Social and cultural dissimilarities in outlooks and the utilisation of various types of cash (e.g. utilisation of credit cards in North America and utilisation of debit cards in Europe) muddle with the job of building an online payment system that is relevant at a global level [81]. The discrepancy in the level of the security required and productivity among individuals of various societies and the degree of advancement worsens the issue.

Buyer's trust and confidence in the customary methods of payment make clients more averse to embrace new innovations. New innovations won't rule the market until clients are sure that their privacy is ensured and satisfactory confirmation of security is safeguarded. New advances likewise need to stand the test of time so as to secure people's confidence, regardless of the fact that it is simpler to use and less expensive than the more established techniques [80].

\section{B. Overcoming Problems in Online Payment Systems}

The payment systems supporting online transactions in a wireless environment should have a level of security equivalent to that of fixed networks. Furthermore, the upcoming online payment applications have to show compatibility with the current traditional payment infrastructure such that there is no problem in operating the existing infrastructure. Nevertheless, the process of making transactions in a wireless environment has several limitations which require the wireless-payment system designers to look for innovative solutions for addressing those constraints. Reducing the computational requirements of the protocols employed is one possible solution; another solution is the replacement of the computation-intense cryptographic operations by more efficient and smarter cryptographic protocols that require less memory resources and computing. Consequently, there is a need of achieving a trade-off between security and performance of transactions for making a secure online payment [3]. Several measures can be taken to overcome various issues in online payment systems. Besides the tangible tools for monitoring frauds like purchase tracking, customer account and validation services, the risk management staff of a certified Level 1 PCC DSS payment processor can be used for precluding frauds. Furthermore, customer service practices like 
merchant accessibility and Know-Your-Customer (KYC) can be employed for substantially reducing or eliminating chargebacks. Cross-border payments which can be expensive, inefficient and slow play a significant role in international trade and require the following developments:

1) Initiatives and authorisations led by Government should be used for regulating fees and payments,

2) Economies of scale can be achieved by multinationals along with the advantage to consolidate credit risk,

3) Up-and-coming transnational systems shall reduce dependence on correspondence networks,

4) Outsourcing shall lower costs and improve processing efficiency, and

5) More effective management of liquidity, costs and credit risk by payment systems.

A certification by Payment Card Industry Data Security Standards (PCI DSS) is a must for every business or merchant that accepts debit or credit cards, offline or online. For online consumers as well as merchants, the bottom line is a secure, seamless and an easy transaction process offered mostly by a PCC DSS Level 1 payment processor [83].

\section{SECURITY OF ONLINE PAYMENT SYSTEMS}

In all information systems, the security of data and information is of significant importance. Data Security involves methodology, technology and practices which guarantee that data is secured from

1) alteration or unintentional change (integrity),

2) unauthorised access (confidentiality), while

3) promptly accessible (availability) to approved clients on demand.

The online payment systems need to have all the above security features; an online payment system which is not secured will not be trusted by its clients. And, trust is extremely important to guarantee acceptance from the clients. The online banking and online payment applications have security issues as they rely upon basic ICT frameworks that make vulnerabilities in economic organisations, businesses and can possibly hurt clients [84].

\section{B. Security Requirements in Online Payment Systems}

A safe economic exchange electronically needs to meet some prerequisites as explored by [85]. They may be stated as follows:

\section{a) Integrity and Authorisation}

Integrity may be characterised as the validity, accuracy and completeness of data as per business qualities and desires. In payment systems, integrity implies that no cash is taken from a client lest a payment is approved by the client. Additionally, clients need not accept any payment without the absolute permission of the clients; this is alluring when clients need to keep away from unwanted bribery [86].

\section{b) Confidentiality}

Confidentiality may be defined as the safety of private or sensitive data from unapproved divulgence. A few organisations included may want to have confidentiality in their exchanges. Confidentiality in this setting implies the confinement of knowledge about different snippets of data which are related to the exchange; the verification of payer/payee, buy content, sum and so forth. Commonly, members included want to guarantee that transactions are secret [86] where untraceability or anonymity is sought, the prerequisite might be to make available this information to only certain specific subsets among the participants.

\section{c) Availability and Reliability}

Availability is guaranteeing that data frameworks and information are prepared for utilisation when they are required; regularly communicated as the rate of time that a framework can be utilised for profitable work. All factions need to have the capacity to make or get payments whenever the need arises [86].

End-user requirements include flexibility, usability, availability, affordability, speed of transactions and reliability.

\section{Enhancing Online Payment Security}

As more and more people are connected to the Internet, the popularity of online commercial activities is growing as well [87]. Nevertheless, the risks associated with online payment systems are factual and multiplying day-by-day. As per the survey conducted by Association of Financial Professionals in the year 2013, it was found that about 60 per cent organisations fell prey to successful or attempted fraud payments whereas up to 63 per cent organisations showed up adoption of new security measures or preparation to do the same in the time to come [88]. Therefore, for their wide acceptance all over the world, online payment methods must follow an efficient protocol ensuring a higher level of security for performing online transactions. The most widely recognised strategy for securing online payments is utilising cryptographic-based innovations, for example, digital signatures and encryption [89]. On application, these innovations lessen speed and proficiency and thus trade off must be made amongst effectiveness and security.

Two commonly used protocols viz. Secure Electronic Transaction (SET) and Security Socket Layer Protocol (SSL) have been identified after analysing the study of [47] ensuring security of online commerce transactions. Among these, SSL is found to be the most commonly used protocol that encodes the whole session between computers involved in the transaction process thereby enabling a safe communication over the Web. In this way, encryption of communication is achieved in SSL using public key cryptography between the client and server. In contrast to this, SET prevents the transfer of the whole credit card number of the user over the Internet by allowing only a part of it to be transferred during the communication process. Furthermore, SET also endows the users with the provision of business data verification, information integration and sensitive information coding by making use of latest technologies like data encoding and digital signatures.

\section{FUTURISTIC CONSIDERATIONS}

The various online payment methods employed by businesses, government and consumers are supported by an assortment of technologies, laws and institutions which combine for transferring value among parties reliably. Like 
every other industry, there is a competition between payment providers who face strong incentives for innovating. Several mechanisms exist in the market simultaneously since every mechanism satisfies a particular requirement. Their reliability and efficiency can be improved only if the consumers agree to embrace new and economical technologies together with the added costs. Eventually, the payment methods are a reflection of the interaction between consumers and providers.

A lot of people are of the view that the payment industry shall go through a dramatic drift in the next ten years, with the existing payment methods getting replaced by totally new online payment systems. But some people are dubious who only expect the existing systems to evolve continuously into systems that are substantially reliant on electronic components. The nature of transformation can be any of these however various obstacles have to be surmounted by consumers as well as producers of the payment services. In this section, some of the opportunities and challenges that the participants of online payment systems (including the Federal Reserve) may face have been discussed. It is observed that consumers, bankers, the Fed, emerging providers and businesses can all impact the way transactions shall be performed in the future if they take interest actively [90].

In order that the commerce runs smoothly, the payment process for purchasing a service or product using a debit or credit card should remain safe, efficient and easy. A number of changes including latest technologies like digital wallets and smart-phones, budding interests in making peer-to-peer payments, demand by consumers to accept payments done by cards and the transitions in buying habits, all have raged a war within this industry as businesses have to fight each other for maintaining their positions. Therefore, there is a tremendous pressure on organisations due to the following reasons [91]:

- New technologies have to be exploited by organisations for simplifying and enhancing the user experience. This is because online payment systems have transformed the entire industry plus the potential for mobile payments, card-reader-equipped smart-phones and contactless cards can all proclaim the subsequent revolution.

- Peer-to-peer payments have to be accommodated since they are responsible for expanding the market beyond the retailer world. Moreover, the necessity of exchanging funds has sparked off innovations past the existing banking model even in developing nations.

- The shift towards a cashless society should be accelerated by incorporating micropayments for vending machines, parking meters, highway tolls, etc. which otherwise involve cash handling inconvenience and other unnecessary costs.

- A firm grip has to be kept on frauds. Since it has been proven by e-commerce that latest technology drives up fraud and brings with itself new threats that include misusing the payment network as well as data theft which can be easily exploited by anyone. For a large number of people, the next frontier is the security concerns in card-not-present transactions.
- The alignment with international technologies and initiatives is also a must. The online payment system is a worldwide infrastructure and its weakest points are the site of attraction for attackers. The anti-fraud initiatives like 3D-Secure and EMV have been launched globally and are to be still rolled out in other markets.

- The compliance of the online payment systems with broader data privacy obligations has to be ensured. In this regard, the collection of PCI standards is used for data breach disclosure laws and privacy mandates, and majority of these laws emphasise on the significance of data related to payments and finance.

The pressures discussed above collectively create a number of challenges for organisations supporting transactions that are performed through online payment systems.

\section{CONCLUSION}

An evolutionary succession has been witnessed by payment methods from cash to cheques, to credit cards and debit cards, and currently to electronic commerce and mobile banking. In this paper, it has been studied that online payment methods are increasingly being used for making daily online as well as onsite purchases. The issues associated with online payment as well as the adoption of electronic commerce for making payments by customers has been discussed in this paper. Furthermore, the advancements in technology supporting mobile transactions and making them more convenient and transparent is developing trust among customers who are becoming habitual of employing this mode of payment. This change in the behaviour of customers showing a transition from the traditional to an advanced online mode of payment is apparent in retailing and banking, and with nearly all available mobile devices. The statistics shown in this study signify that the number of customers employing online mode of payment and making online transactions are continuously growing, hinting at an everlasting acceptance of online payment systems from academia as well as industry. However, the adoption and deployment of several rising technologies carry new opportunities and challenges to the implementation and design of secure online payment systems in the present day as well as in near future. This study concludes that a better integration of online payment systems with the present financial and telecommunication infrastructure is necessary for a propitious future of this payment mode. Furthermore, establishing a common standard for a variety of service providers, improving the compatibility with a large number of customers, overcoming privacy and security concerns and employing the latest technology could facilitate expeditious adoption of online payment methods and expand the market for such a mode of payment. Future work may be directed towards the legalisation of various factors responsible for contributing in the efficacious adoption of online payment systems all over the world.

\section{REFERENCES}

[1] H. Yu, K. Hsi and P. Kuo, "Electronic payment systems: an analysis and comparison of types", Technology in Society, vol. 24, no. 3, pp. 331$347,2002$.

[2] S. Kungpisdan, "Design and Analysis of Secure Mobile Payment Systems," PhD dissertation, Faculty of Information Technology, Monash University, 2005. 
[3] J. Tellez Isaac and Z. Sherali, "Secure Mobile Payment Systems", IT Professional, vol. 16, no. 3, pp. 36-43, 2014.

[4] J. Sun, P. Ahluwalia, K.S. Koong, "The more secure the better? A study of information security readiness", Industrial Management \& Data Systems, vol. 111, no. 4, pp. 570-588, 2011.

[5] P. Aigbe and J. Akpojaro, "Analysis of Security Issues in Electronic Payment Systems", International Journal of Computer Applications, vol. 108, no. 10, pp. 10-14, 2014.

[6] C.K. Ayo, J.O. Adewoye and A.A. Oni, "The State of E-Banking Implementation in Nigeria: A Post-Consolidation Review", Journal of Emerging Trends in Economics and Management Sciences, vol. 1, no. 1, pp. 37-45, 2010.

[7] O.S. Oyewole, M. Abba and J.G. El-maude, "E-banking and Bank Performance: Evidence from Nigeria", International Journal of Scientific Engineering and Technology (IJSET), vol. 2, no. 8, pp. 766771, 2013.

[8] O.S Oyewole, J.G. El-Maude, M. Abba and M.E. Onuh, "Electronic Payment System and Economic Growth: A Review of Transition to Cashless Economy in Nigeria", International Journal of Scientific and Engineering Research, vol. 2, no. 9, pp. 913-918, 2013.

[9] A. Singh, K. Singh, Shahazad, M.H. Khan and M. Chandra, "A Review: Secure Payment System for Electronic Transaction", International Journal of Advanced Research in Computer Science and Software Engineering, vol. 2, no. 3, pp. 236-243, 2012.

[10] Shilpa and P. Sharma, "Advance Technique for Online Payment Security in E-Commerce: "Double Verification"”, International Journal on Computer Science and Engineering, vol. 5, no. 6, pp. 508-513, 2013.

[11] D. Abrazhevich, Electronic payment systems: A user-centered perspective and interaction design, Dennis Abrazhevich; Eindhoven, Netherland: Technische, p. 189, 2004.

[12] S. Roy and I. Sinha, "Determinants of Customers' Acceptance of Electronic Payment System in Indian Banking Sector-A Study", International Journal of Scientific and Engineering Research, vol. 5, no. 1, pp. 177-187, 2014.

[13] M.A. Kabir, S.Z. Saidin and A. Ahmi, "Adoption of e-Payment Systems: A Review of Literature", International Conference on ECommerce, Kuching, Sarawak, 2015, pp. 112-120.

[14] B.C. McNurlin and R.H. Sprague, Information Systems Management in Practice, Prentice-Hall International; 1989 Jan 3.

[15] A. Boonstra and J. De Vries, "Analyzing Inter-Organizational Systems from a Power and Interest Perspective", International Journal of Information Management, vol. 25, no. 6, 2005, pp. 485-501.

[16] R.L. Kumar and C.W. Crook, "A Multi-Disciplinary Framework for The Management of Interorganizational Systems", ACM SIGMIS Database, vol. 30, no. 1, pp. 22-37, 1999.

[17] A.Briggs and L. Brooks, "Electronic Payment Systems Development in a Developing Country: The Role of Institutional Arrangements", The Electronic Journal of Information Systems in Developing Countries, vol. 49, no. 3, pp. 1-16, 2011.

[18] World Payments Report 2014 [Online]. p. 1-58. Available from: https://www.fr.capgemini.com/resource-fileaccess/resource/pdf/world_payments_report_2014.pdf [Accessed: 05February-2017].

[19] 2016 World Payments Report [Online]. p. 1-47. Available from: http://www.astrid-

online.it/static/upload/worl/world_payments_report_wpr_2016.pdf [Accessed: 05-February-2017].

[20] O. Slozko and A. Pelo, "Problems and Risks of Digital Technologies Introduction into E-Payments", Transformation in Business \& Economics, vol. 14, no. 1, pp. 42-59, 2015.

[21] "Innovation in Electronic Payment Adoption: The case of small retailers" [Online]. Washington, DC, USA: The World Bank Group; 2016 p. 1-51. Available: http://www3.weforum.org/docs/Innovative_Solutions_Accelerate_Adopt ion_Electronic_Payments_Merchants_report_2016.pdf [Accessed: 04February-2017].
[22] P.M. Ogedebe and B.P. Jacob, "E-payment: Prospects and Challenges in Nigerian Public Sector", International Journal of Modern Engineering Research, vol. 2, no. 5, pp. 3104-3106, 2012.

[23] O. Adeoti and K. Osotimehin, "Adoption of Point of Sale Terminals in Nigeria: Assessment of Consumers' Level of Satisfaction", Research Journal of Finance and Accounting, vol. 3, no. 1, pp. 1-6, 2012.

[24] K. Kaur and A. Pathak, "E-Payment System on E-Commerce in India", International Journal of Engineering Research and Applications, vol. 5, no. 2, pp. 79-87, 2015.

[25] R. Kalakota and A.B. Whinston, "Electronic commerce: a manager's guide", Addison-Wesley Professional; 1997.

[26] D. Hancock and D.B. Humphrey, "Payment transactions, instruments, and systems: A survey", Journal of Banking \& Finance, vol. 21, no. 11, pp. 1573-1624, 1997.

[27] T. Agimo, "Better Practice Checklist for ePayment". Australia Government Information Management Office. 2004. [Online]. Available: $\mathrm{http}: / /$ www.finance.gov.au/agimoarchive/publications_noie/2000/04/better_practice_checklist_for_epaym ent.html [Accessed: 01-February-2017]

[28] S.K. Antwi, K. Hamza and S.W. Bavoh, "Examining the Effectiveness of Electronic Payment System in Ghana: The Case of e-ZWICH in the Tamale Metropolis", Research Journal of Finance and Accounting, vol. 6, no. 2, pp. 163-177, 2015.

[29] C. Lin and C. Nguyen, "Exploring e-payment adoption in vietnam and Taiwan”, Journal of Computer Information Systems, vol. 51, no. 4, pp. 41-52, 2011.

[30] T.H. Shon and P.M. Swatman, "Identifying Effectiveness Criteria for Internet Payment Systems", Internet Research, vol. 8, no. 3, pp. 202218, 1998.

[31] J.S. Gans and R. Scheelings, "Economic Issues Associated with Access to Electronic Payments Systems", Australian Business Review. Available at SSRN: http://ssrn.com/abstract $=1100903$

[32] J. Hord, "How Electronic Payment Works", [Online]. HowStuffWorks. Available: http://money.howstuffworks.com/personal-finance/onlinebanking/electronic-payment1.htm [Accessed: 23-February-2017]

[33] W. Ming-Yen Teoh, S. Choy Chong, B. Lin and J. Wei Chua, "Factors Affecting Consumers' Perception of Electronic Payment: An Empirical Analysis", Internet Research, vol. 23, no. 4, pp. 465-485, 2013.

[34] S. Oh, "A Stakeholder Perspective on Successful Electronic Payment Systems Diffusion", In System Sciences, 2006. HICSS'06. Proceedings of the 39th Annual Hawaii International Conference on, vol. 8, 2006, pp. 186b-186b. IEEE.

[35] M. Al-Laham, H. Al-Tarawneh and N. Abdallat, "Development of Electronic Money and its Impact on the Central Bank Role and Monetary Policy", Issues in Informing Science and Information Technology, vol. 1, no. 6, pp. 339-349, 2009.

[36] M. Baddeley, "Using e-cash in the new economy: An economic analysis of micro-payment systems", Journal of Electronic Commerce Research, vol. 5, no. 4, pp. 239-253, 2004. [Online]. Available: http://web.csulb.edu/journals/jecr/issues/20044/Paper3.pdf

[37] B. Meng and Q. Xiong, "Research on electronic payment model," in The 8th International Conference on Computer Supported Cooperative Work in Design Proceedings, 2004, pp. 597-602.

[38] N. Asokan, "Fairness in electronic commerce," Ph.D. dissertation, Dept. Computer Science, University of Waterloo, Ontario, Canada, 1998.

[39] S. Singh, "Emergence of payment systems in the age of electronic commerce: The state of art," Global Journal of International Business Research, vol. 2, no. 2, pp. 17-36, 2009.

[40] C. Merritt, "Mobile money transfer services: The next phase in the evolution in person-to-person payments," Federal Reserve Bank of Atlanta, GA, White Paper, 2010.

[41] Compass Plus, “Mobile banking: One size doesn't fit all," Compass Plus Corp., Nottingham, United Kingdom, White Paper. [Online]. Available: http://www.compassplus.com/collateral/whitepapers/336

[42] C. P. Beshouri and J. Gravråk, "Capturing the promise of mobile banking in emerging markets," McKinsey \& Comp., New York, NY, 2010. 
[43] B. Gates and M. Gates, "Mobile banking will help the poor transform their lives". [Online]. Available: https://www.gatesnotes.com/2015Annual-Letter?page=3\&lang=en [Accessed: 29-Apr-2017].

[44] R. Boden, "Wearable smart stamp to support NFC payments". [Online]. Available: http://www.nfcworld.com/2016/04/18/344048/wearablesmart-stamp-support-nfc-payments. [Accessed: 29-Apr-2017].

[45] S. Ghosh, A. Majumder, J. Goswami, A. Kumar, S. Mohanty and B. Bhattacharyya, "Swing-Pay: One Card Meets All User Payment and Identity Needs: A Digital Card Module using NFC and Biometric Authentication for Peer-to-Peer Payment", IEEE Consumer Electronics Magazine, vol. 6, no. 1, pp. 82-93, 2017.

[46] K. Peffers and W. Ma, "An Agenda for Research about the Value of Payment Systems for Transactions in Electronic Commerce", JITTA: Journal of Information Technology Theory and Application, vol. 4, no. 4, pp. 1, 2003

[47] A. Koponen, "E-Commerce, Electronic Payments", Helsinki University of Technology, Telecommunications Software and Multimedia Laboratory, 2006.

[48] C. Paunov and G. Vickery, "Online Payment systems for E-Commerce". Organization for Economic Co-operation and development (OECD), 2006.

[49] Capgemini and The Royal Bank of Scotland (RBS), "World Payments Report 2013", Capgemini and The Royal Bank of Scotland, 2013.

[50] C.J. Hoofnagle, J.M. Urban and S. Li, "Mobile Payments: Consumer benefits and new privacy concerns", BCLT Research Paper, pp. 1-19, 2012.

[51] N. Doan, "Consumer adoption in Mobile Wallet", The Turku University of Applied Sciences, 2014.

[52] T. Husson, "The Future of Mobile Wallets lies beyond Payments", U.S.A.: Forrester Research Inc., 2015.

[53] K. Nuthan and P.C. Rashmi, "An E-payment System: Literature Review", First International Conference on Recent Advances in Science \& Engineering. 2014.

[54] K. Jamdaade and H. Champaneri, "A Review: Secured Electronic Payment Gateway", International Journal of Technology Enhancements and Emerging Engineering Research, vol. 3, no. 6, pp. 70-72, 2015.

[55] V.P. Gulati and S. Srivastava, "The Empowered Internet Payment Gateway", In International Conference on E-Governance, 2007, pp. 98107.

[56] M. Niranjanamurthy, "E-commerce: Recommended Online Payment Method-PayPal", International Journal of Computer Science and Mobile Computing, vol. 3, no. 7, pp. 669-679.

[57] "Best Payment Gateways | Formstack" [Online]. Formstack.com. Available from: https://www.formstack.com/infographics/best-paymentgateway [Accessed: 24-February-2017].

[58] O. Oginni, Impact of Electronic Banking on Commercial Banks' Performance, Lap Lambert Academic Publishing. Germany: Saarbucken. ISBN 978-3-659-42758-9.

[59] T.T. Siyanbola, "The Effect of Cashless Banking on Nigerian Economy", eCanadian Journal of Accounting and Finance, vol. 1, no. 2, pp. 9-19, 2013.

[60] M. Omotunde, T. Sunday and A.T. John-Dewole, "Impact of cashless economy in Nigeria. Greener Journal of Internet", Information and Communication Systems, vol. 1, no. 2, pp. 40-43, 2013.

[61] S. Newstead, "Cashless payments underpin economic growth (a)Euromoney" [Online]. Euromoney. 2012 Available: http://www.euromoney.com/Article/3122985/Cashless-paymentsunderpin-economic-growth.html [Accessed: 11-Feb-2017].

[62] World Payments Report 2012 [Online]. p. 1-54. Available: https://www.capgemini.com/resource-fileaccess/resource/pdf/The_8th_Annual_World_Payments_Report_2012.p df [Accessed: 05-February-2017]

[63] I. Hasan, T. De Renzis and H. Schmiedel, "Retail Payments and Economic Growth", Bank of Finland Research Discussion Papers 19. 2012.

[64] M. Zandi, V. Singh and J. Irving, "The Impact of Electronic Payments on Economic Growth", Moody's Analytics: Economic and Consumer Credit Analytics. 2013 Jan.
[65] D. Fernandez and D. Fernandez, "The Future of Cashless Economies: Why Governments and Consumers Should Migrate to Cashless Payments", Netclearance Systems, 2017. [Online]. Available: http://www.netclearance.com/blog/2017/1/6/the-future-of-cashlesseconomies-why-governments-and-consumers-should-migrate-tocashless-payments. [Accessed: 30- Apr- 2017].

[66] "What is an E-Payment System?" [Online]. SecurionPay - Payment Gateway. Available: https://securionpay.com/blog/e-payment-system/ [Accessed: 04-February-2017].

[67] J. McGrath, "Cashing in on payments tech innovations - raconteur.net", Raconteur. [Online]. Available: https://www.raconteur.net/technology/cashing-in-on-payments-techinnovations. [Accessed: 19- Apr- 2017].

[68] Accenture, "North America consumer digital payments survey: When it comes to payments today, the customer rules". [Online]. Available: https://www.accenture.com/t20151021T165757_w___usen/_acnmedia/Accenture/next-gen/na-payment-survey/pdfs/AccentureDigital-Payments-Survey-North-America-AccentureExecutiveSummary.pdf. [Accessed: 25-Apr-2017]

[69] "Consumer payments study". [Online]. Available: http://tsys.com/Assets/TSYS/downloads/rs_2014-consumerpaymentsstudy.pdf. [Accessed: 29-Apr-2017]

[70] K. Cash, "Stratos, Coin, Plastc, SWYP: Sizing up multiaccount cards". [Online]. Available: https://www.nerdwallet.com/blog/creditcards/stratos-coin-plastc-swyp-sizing-multiaccount-cards. [Accessed: 28-Apr-2017]

[71] Accenture, "Mobile payments survey insights: Driving value and adoption consumers want more!". [Online]. Available: https://www.accenture.com/in-en/ /media/Accenture/ConversionAssets/DotCom/Documents/Global/PDF/Industries_5/AccentureMobile-Payment-Infographic.pdf. [Accessed: 28-Apr-2017]

[72] K. Cash, "Stratos, Coin, Plastc, SWYP: Sizing up multiaccountcards". [Online]. Available: https://www.nerdwallet.com/blog/creditcards/stratos-coin-plastc-swyp-sizing-multiaccount-cards. [Accessed: 27-Apr-2017]

[73] "Survey: Consumers adopting mobile payments, but at a slow pace", Networld Media Group. [Online]. Available: http://www.mobilepaymentstoday.com/news/surveyconsumersadopting-mobile-payments-but-at-a-slow-pace/. [Accessed: 29-Apr-2017]

[74] F. Fiallos and L. Wu, "Digital Money: Future Trends and Impact on Banking", Financial Institutions, and eBusiness, 2005.

[75] "Will m-payment take off?" [Online]. Applb-1378907147.us-east1.elb.amazonaws.com. 2005 Available: http://applb-1378907147.useast-1.elb.amazonaws.com/popup/print/491364 [Accessed: 28-January2017].

[76] J. Hord, "How Electronic Payment Works" [Online]. HowStuffWorks. Available: http://money.howstuffworks.com/personal-finance/onlinebanking/electronic-payment2.htm [Accessed: 12-February-2017].

[77] D.B. Humphrey, M. Kim and B. Vale, "Realizing the Gains from Electronic Payments: Costs, Pricing, and Payment Choice", Journal of Money, credit and Banking, vol. 33, no. 2, pp. 216-234, 2001.

[78] A. Appiah and F. Agyemang, "Electronic retail payment systems: user acceptability and payment problems in Ghana", School of Management Business Administration Blekinge Institute of Technology, Sweden. 2006.

[79] D.B. Humphrey, L.B. Pulley and J.M. Vesala, "The Check's in the Mail: Why the United States Lags in the Adoption of Cost-Saving Electronic Payments", Journal of Financial Services Research, vol. 17, no. 1, pp. $17-39,2000$.

[80] D. Kumaga, "The Challenges of Implementing Electronic Payment Systems-The Case of Ghana's E-Zwich Payment System", Master's Thesis, 2011.

[81] W. Taddesse and T.G. Kidan, "E-Payment: Challenges and Opportunities in Ethiopia. United Nations Economic Commission for Africa. 2005 Oct.

[82] B.B. Mishra, "The Development of E-payment and Challenges in Nepal. An e-book", pp. 159-168, 2008. 
[83] E. Feinstein, "Top 5 Challenges in Online Payments and How to Overcome Them", Direct Pay Online. [Online]. Available: http://blog.directpay.online/top-5-challenges-in-online-payments-andhow-to-overcome-them. [Accessed: 29-Apr-2017].

[84] G. Worku, "Electronic-banking in Ethiopia-Practices, Opportunities and Challenges", Journal of Internet Banking and Commerce, vol. 15, no. 2, pp. 1, 2010.

[85] H. Ismaili, H. Houmani and H. Madrroumi, "A Secure Electronic Transaction Payment Protocol Design and Implementation", Morocco: International Journal of Advanced Computer Science and Applications, vol.5, no.5, pp. 172-180, 2014.

[86] N. Asokan, P. Janson, M. Steiner and M. Waidner, "Electronic Payment Systems", IBM Thomas J. Watson Research Division, 1996.

[87] E. O'Raghallaigh, "Security Issues in E-Commerce", Web Science, 2010.
[88] M. Urban, "The Challenges \& Opportunities in Electronic Payments Fraud | Bank Systems \& Technology”, Bank Systems \& Technology, 2014. [Online]. Available: http://www.banktech.com/the-challengesand-opportunities-in-electronic-payments-fraud/a/d-id/1279151. [Accessed: 29- Apr- 2017].

[89] W. Taddesse and T.G. Kidan, "E-Payment: Challenges and Opportunities in Ethiopia", United Nations Economic Commission for Africa. 2005 Oct.

[90] “Our Payments System: Challenges and Opportunities”, clevelandfed, 1997. [Online]. Available: https://www.clevelandfed.org/newsroomand-events/publications/annual-reports/ar-1997-our-paymentssystem/ar-199702-essay.aspx. [Accessed: 21- Apr- 2017].

[91] "Payment Processing: Challenges, Risks, and Solutions", Thalesesecurity.com. [Online]. Available: https://www.thalesesecurity.com/solutions/by-technology-focus/payment-processing. [Accessed: 29-Apr-2017]. 